\title{
DNA Nanoparticles for Improved Protein Synthesis In Vitro
}

\author{
Robertas Galinis ${ }^{+}$, Greta Stonyte ${ }^{+}$, Vaidotas Kiseliovas, Rapolas Zilionis, Sabine Studer, \\ Donald Hilvert, Arvydas Janulaitis, and Linas Mazutis*
}

\begin{abstract}
The amplification and digital quantification of single DNA molecules are important in biomedicine and diagnostics. Beyond quantifying DNA molecules in a sample, the ability to express proteins from the amplified DNA would open even broader applications in synthetic biology, directed evolution, and proteomics. Herein, a microfluidic approach is reported for the production of condensed DNA nanoparticles that can serve as efficient templates for in vitro protein synthesis. Using phi29 DNA polymerase and a multiple displacement amplification reaction, single DNA molecules were converted into DNA nanoparticles containing up to about $10^{4}$ clonal gene copies of the starting template. DNA nanoparticle formation was triggered by accumulation of inorganic pyrophosphate (produced during DNA synthesis) and magnesium ions from the buffer. Transcription-translation reactions performed in vitro showed that individual DNA nanoparticles can serve as efficient templates for protein synthesis in vitro.
\end{abstract}

Compartmentalization and amplification of single DNA molecules inside nano- or picoliter-sized wells ${ }^{[1]}$ and droplets ${ }^{[2]}$ has opened up new opportunities for biomedical and biological sciences. The discrete nature of compartments enables digital quantification of absolute numbers of nucleic acids in a sample, ${ }^{[3]}$ accurate estimation of copy-number variation, ${ }^{[4]}$ detection of pathogens ${ }^{[5]}$ and rare cancer mutations, ${ }^{[6]}$ as well as other applications. ${ }^{[7]}$

The most common method of amplifying DNA in a sample involves the polymerase chain reaction (PCR). However, for droplet microfluidics experiments, the large temperature gradient required for PCR is a major drawback that can cause droplet coalescence and loss of compartmentalization. In addition, amplification of long ( $>1 \mathrm{~kb})$ templates is often inefficient, leading to decreased reaction yields. In contrast, DNA amplification under isothermal reaction conditions has been shown to generate large amounts of

$[*]$ R. Galinis, ${ }^{[+]}$G. Stonyte ${ }^{[+]}$V. Kiseliovas, R. Zilionis, Prof. A. Janulaitis, Dr. L. Mazutis

Institute of Biotechnology Vilnius University

8 Graiciuno street, 02241 Vilnius (Lithuania)

E-mail: linas.mazutis@bti.vu.It

S. Studer, Prof. D. Hilvert

Laboratory of Organic Chemistry, ETH Zurich

Vladimir-Prelog-Weg 1-5, 8093 Zurich (Switzerland)

$\left.{ }^{+}\right]$These authors contributed equally to this work.

(-) Supporting information for this article is available on the WWW under http://dx.doi.org/10.1002/anie.201511809.

Of (C) 2016 The Authors. Published by Wiley-VCH Verlag GmbH \& Co. $\mathrm{KGaA}$. This is an open access article under the terms of the Creative Commons Attribution-NonCommercial License, which permits use, distribution and reproduction in any medium, provided the original work is properly cited and is not used for commercial purposes. material from a single-copy DNA template,${ }^{[8]}$ circumventing potential problems associated with emulsion stability. Moreover, the ability to amplify DNA and then express proteins from the clonally amplified template would greatly increase the scope of potential applications. For example, synthetic biology, directed evolution, and large-scale proteomics screens would benefit from techniques that do not rely on protein expression in living systems.

A major challenge for in vitro expression of proteins is the relatively large amounts of DNA template needed-on the order of $500 \mathrm{ng}$ DNA $\left(\approx 10^{9}\right.$ gene copies $)$ per $50 \mu \mathrm{L}$ reaction $^{[9]}$ - since protein synthesis from a single DNA copy is rather inefficient. An alternative approach is to compartmentalize single DNA molecules in droplets and perform clonal amplification followed by the in vitro transcriptiontranslation (IVTT) step. ${ }^{[10]}$ However, the need for sophisticated microfluidic chips to perform complex droplet manipulations on-chip restricts broader use and further applications.

Herein we report a new approach for in vitro synthesis of proteins using condensed DNA nanoparticles comprising up to about $10^{4}$ copies of the clonally amplified DNA template. We employed a droplet microfluidics approach to convert single DNA molecules into DNA nanoparticles by a multiple displacement amplification (MDA) reaction driven by the bacteriophage phi29 DNA polymerase. Intriguingly, we found that inorganic pyrophosphate (produced during isothermal DNA synthesis) and magnesium ions are a prerequisite for DNA condensation into the crystalline-like globular structures. This process was enhanced when the DNA amplification reaction was performed inside droplets, which we attribute to the confined volumes and spatial accumulation of the reaction products. To demonstrate the biological functionality of the DNA nanoparticles, we used them in IVTT reactions and observed improved protein expression yields relative to standard assay conditions.

We first encapsulated pUC19 plasmid DNA in monodisperse $3 \mathrm{pL}$ droplets together with phi29 DNA polymerase, exo-resistant random DNA primers, pyrophosphatase, and other reaction components (see the Supporting Information, Materials and Methods section) necessary for DNA synthesis by an MDA mechanism. ${ }^{[8]}$ The plasmid concentration was adjusted so that one droplet contained one DNA molecule on average $(\lambda=1.0)$. The microfluidics device used for encapsulation (Figure 1) was operated at a frequency of $4.6 \mathrm{kHz}$, allowing collection of $10^{6}$ droplets in less than an hour. ${ }^{[10]}$ The collected emulsion was incubated at $30^{\circ} \mathrm{C}$ for $15 \mathrm{~h}$ to allow the isothermal DNA amplification reaction to occur and was then stained with the cyanine dye SYBR Green I, which becomes fluorescent upon binding double-stranded DNA (dsDNA; Figure 1c). 
a

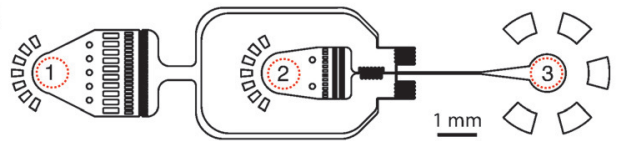

b
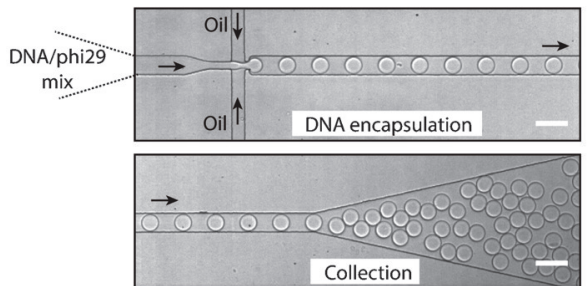

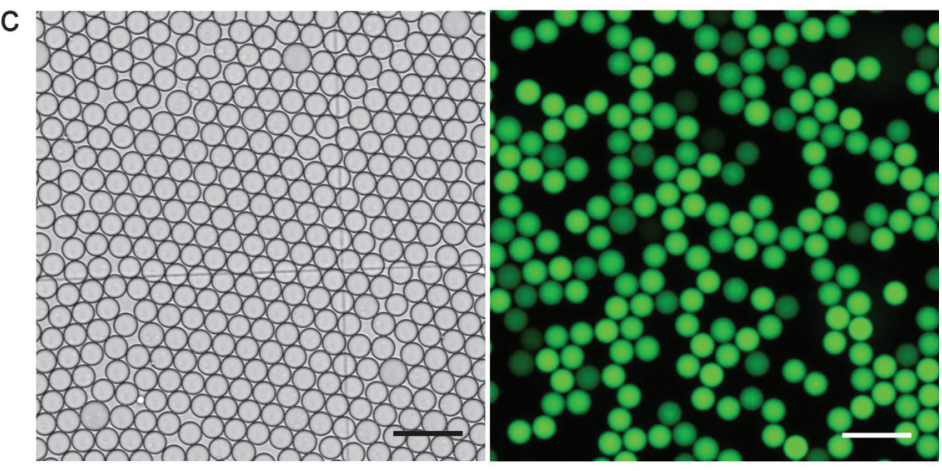

Figure 1. Design and operation of the microfluidics device. a) The microfluidics device, showing 1) the inlet for the continuous phase, 2) the inlet for the MDA reaction mix, and 3) the droplet collection outlet. b) Still images of droplet production and collection. c) Bright field and fluorescence images of an emulsion after an MDA reaction. Droplets containing amplified DNA exhibit green fluorescence, whereas droplets lacking a template are dark. Scale bars in (b) and (c) $=50 \mu \mathrm{m}$.

The Poisson equation predicts that random partitioning of $0.57 \mathrm{pM}$ DNA template into $3 \mathrm{pL}$ droplets $(\lambda=1.0)$ will afford a population of $37 \%$ empty and $63 \%$ occupied droplets, with about $37 \%$ of the droplets containing one DNA molecule and about $26 \%$ containing two or more. Digital fluorescence analysis of the emulsion revealed that about $58 \%$ of the droplets were fluorescent after isothermal amplification. Additionally, serial dilutions of the DNA sample confirmed that droplet occupancy followed a Poisson distribution (see Figure S1 in the Supporting Information). The small differences in occupancy between the experimental results and theoretical predictions can be attributed to abortive amplification of damaged DNA plasmids, losses caused by nonspecific adsorption in the system, or pipetting errors. As expected, negative controls having no DNA template afforded few fluorescent droplets (about $0.4 \%$ ), corresponding to about $2.0 \mathrm{fm}$ ambient DNA.

Fluorescence imaging of an emulsion after the MDA reaction revealed a mean fluorescence intensity of $440 \pm$ $88 \mathrm{RFU}$ (RFU = relative fluorescence units) for occupied droplets, which translates to $110 \pm 30 \mathrm{ng} \mu \mathrm{L}^{-1}$ of DNA, or about a $10^{5}$-fold amplification of the starting template (Figure S2). Previous reports found a similar degree of amplification when phi29 reactions were performed in bulk ${ }^{[8]}$ and in droplets. ${ }^{[10]}$

Unexpectedly, during the course of DNA amplification, we noticed that excluding pyrophosphatase (PPase) from the reaction mix leads to the formation of highly fluorescent nanoparticles inside the droplets (Figure 2a). PPase is an enzyme that catalyzes the hydrolysis of inorganic pyrophosphate into two orthophosphate molecules ${ }^{[1]}$ and is used to increase the amplification yields of nucleic acids. ${ }^{[8]}$ To confirm that inorganic pyrophosphate is indeed a prerequisite for formation of condensed DNA nanoparticles, we encapsulated pUC19 DNA $\left(0.23 \mu \mathrm{M} ; \lambda=4 \times 10^{5}\right)$ dissolved in $8 \mathrm{~mm}$ Tris$\mathrm{HCl}$ buffer ( $8 \mathrm{~mm}$; $\mathrm{pH}$ 7.6) containing sodium pyrophosphate (4 $\mathrm{mm})$ and $\mathrm{MgCl}_{2}(10 \mathrm{~mm})$, while excluding other components such as the phi29 enzyme, primers, and deoxynucleoside triphosphates (dNTPs) from the reaction mix. As expected, we observed formation of fluorescent precipitants in the droplets (Figure S3), confirming that inorganic pyrophos-
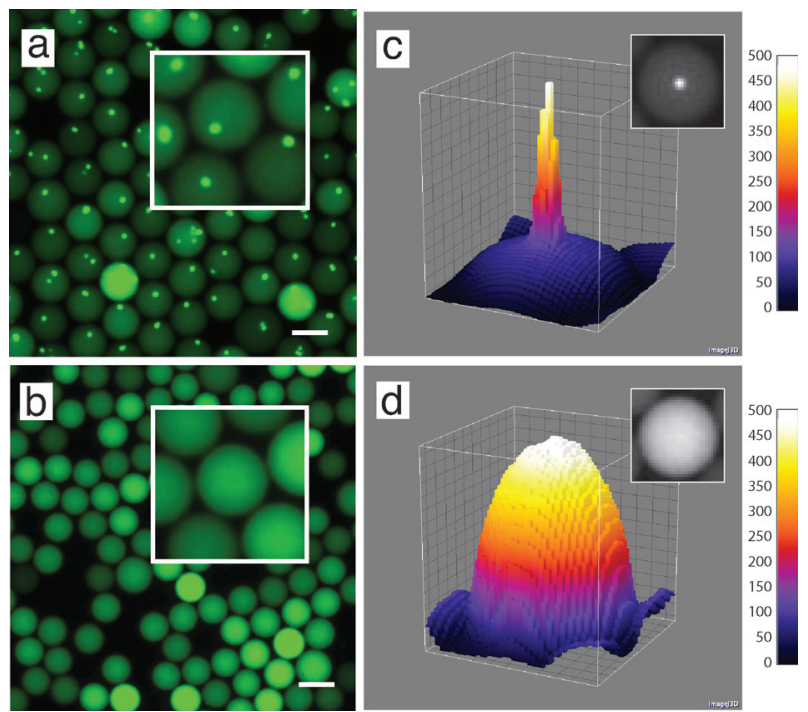

Figure 2. DNA nanoparticle generation. a) DNA nanoparticle formation induced by inorganic pyrophosphate and magnesium ions during a phi29-catalyzed DNA polymerization reaction in the absence of the PPase enzyme. For visualization purposes, the initial DNA template concentration was set at $\lambda \approx 1.0$, and as a result, a small fraction of droplets appears with two or more DNA particles. b) The same reaction as in (a), but in the presence of the PPase enzyme. Insets in (a) and (b): magnified views of the emulsions; the DNA nanoparticles are evident as localized and intensely fluorescent objects within the droplets. Scale bars $=20 \mu \mathrm{m}$. The composition of reaction mixtures is described in the Material and Methods section in the Supporting Information. c) A 3D fluorescence intensity profile of a single droplet containing a single DNA nanoparticle. d) A 3D fluorescence intensity profile of a droplet with $\approx 10^{5}$ copies of a DNA template. Color bars indicate an approximate DNA copy number per single pixel $(0.66 \mu \mathrm{m}$ size).

phate and magnesium ions are major triggers for the formation of DNA nanoparticles. In agreement with our observations, others have recently reported the formation of DNA/RNA:pyrophosphate:Mg complexes under PCR/RCA conditions $\left(\mathrm{RCA}=\right.$ rolling-circle amplification).$^{[12]}$ Taken together, our findings and the literature data allow us to conclude that inorganic pyrophosphate, produced during the 
phi29-driven DNA amplification reaction, associates with magnesium ions and promotes condensation of newly synthesized DNA in the particle.

Electrophoretic analysis confirmed that DNA amplification, with or without PPase, was specific (Figure S4). We used digital image analysis to quantify the number of DNA copies and found that single DNA nanoparticles contained about 6000 copies of the original template (Figure 2c; Note S1 in the Supporting Information). To gain further insight into the structural features of the DNA material produced during isothermal amplification, we broke the droplets and analyzed the released material by transmission electron microscopy (TEM), scanning electron microscopy (SEM), atomic force microscopy (AFM), and dynamic light scattering (DLS). The DLS measurements confirmed the presence of particles with a diameter of $152 \pm 37 \mathrm{~nm}$ (Figure $3 \mathrm{a}$ ), in good agreement
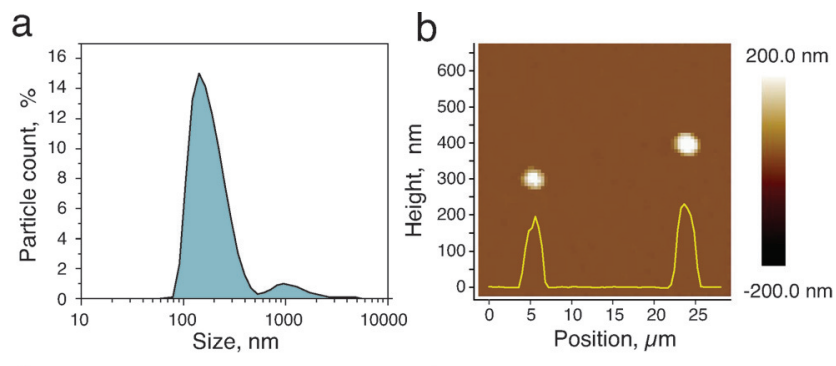

C

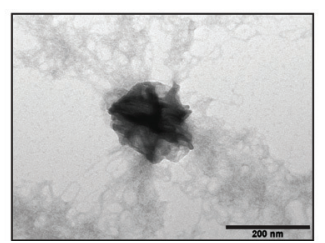

d

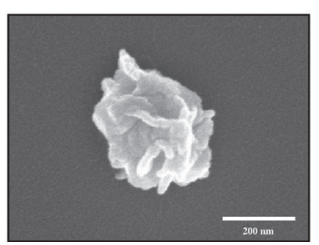

Figure 3. DNA nanoparticle characterization. a) DLS measurements, showing that $93.5 \%$ of the particles have diameters of $152 \pm 37 \mathrm{~nm}$. b) AFM measurements on two representative DNA nanoparticles. The size of the DNA nanoparticles was estimated to be approximately $200 \mathrm{~nm}$ (yellow trace overlaid on the AFM image). c) TEM and d) SEM images of single DNA nanoparticles. Scale bars in (c) and (d) $=200 \mathrm{~nm}$.

with the AFM measurements (Figure 3b). The TEM and SEM analysis revealed individual, densely packed nanoparticles of uniform size and a petal-like surface structure (Figure $3 \mathrm{c}$ and $3 \mathrm{~d}$ ). Similar crystalline-like, globular microstructures were recently generated from short, circular $\mathrm{DNA}^{[13]}$ and $\mathrm{RNA}^{[14]}$ templates. Nevertheless, despite detailed microscopic characterization of these DNA/RNA microstructures, the importance of pyrophosphate:magnesium complexes for the nucleation and condensation process remained unappreciated. Performing the MDA reaction in bulk at different template concentrations $(0.1-100 \mathrm{pm})$ led to the formation of DNA aggregates, albeit without clearly defined structures (Figure S5).

To test whether individual DNA nanoparticles (DNANPs) could serve as templates for gene expression, we performed IVTT reactions (Figure 4). To monitor protein production, we used a pET29b(+) expression plasmid encod- a

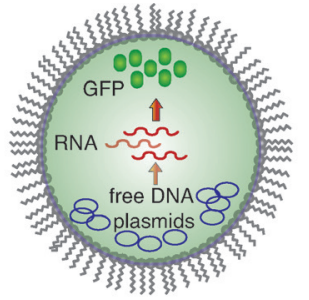

Free plasmid $(\lambda=7000)$

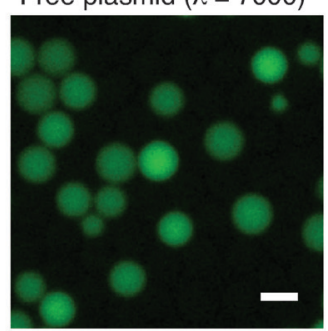

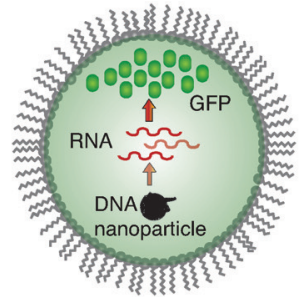

DNA nanoparticle $(\lambda \sim 0.05)$

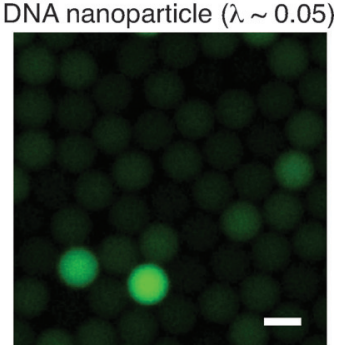

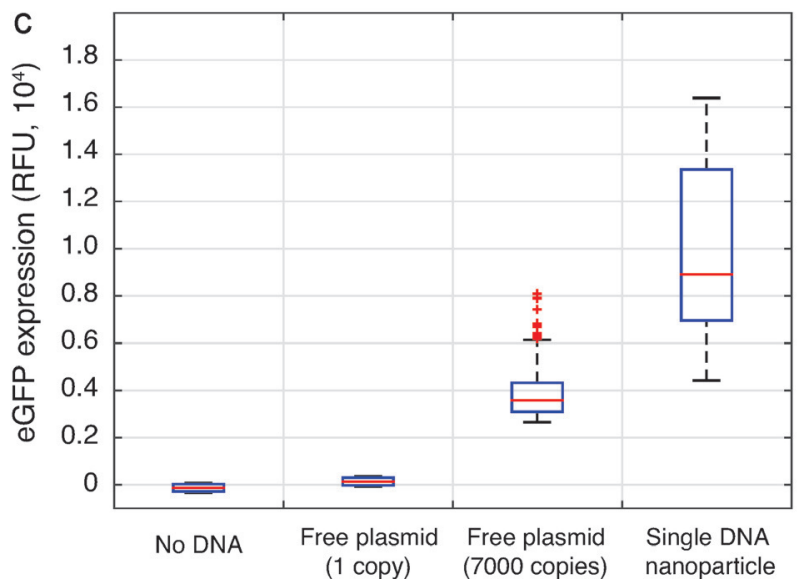

Figure 4. IVTT reactions to produce eGFP. a) Schematic of an IVTT reaction carried out in droplets. b) Fluorescence images of an IVTT emulsion prepared with free DNA plasmid at $\lambda \approx 7000$ (left) and DNA nanoparticles at $\lambda \approx 0.05$ (right). For visualization purposes, droplets containing plasmids were mixed with droplets lacking DNA (left panel). Droplets without DNA showed no fluorescence and appear as dark droplets interspersed among bright droplets. Scale bars $=20 \mu \mathrm{m}$. c) The median yield of eGFP expression. The results are displayed as a box-plot, with median values indicated as red lines. The differences detected for eGFP expression in droplets containing free plasmid (7000 copies of the template) and a single DNA nanoparticle (carrying about 6000 copies of the template) were statistically significant $\left(P=3.2 \times 10^{-9}\right)$ as judged by the Student's $t$-test.

ing enhanced green fluorescent protein (eGFP) under the control of the T7 promoter. DNA-NPs were first prepared from this plasmid encapsulated in droplets and were then purified by preparative agarose gel electrophoresis and centrifugation. The purified material largely retained its densely packed structure, judging from TEM images of purified particles (Figure S6). Additionally, electrophoretic analysis of the sample confirmed highly specific amplification of the original template (Figure S7).

To evaluate the in vitro biological functionality of the synthesized material we added purified DNA-NPs to the IVTT mix and created $5 \mathrm{pL}$ droplets using the same microfluidics device shown in Figure 1. We used diluted suspensions 
of DNA-NPs $(\lambda=0.05)$ to ensure that each droplet contains no more than a single DNA nanoparticle. The collected emulsion was incubated at $37^{\circ} \mathrm{C}$ for $3 \mathrm{~h}$ to allow in vitro gene expression to occur. Fluorescence analysis confirmed that droplets containing single DNA-NPs expressed high levels of the eGFP, as evidenced by the appearance of highly fluorescent droplets (Figure 4b; Figure S8). Considering that a single DNA-NP carries approximately 6000 copies of an initial template (Note S1 in the Supporting Information), we compared eGFP yields for droplets containing similar amounts of free plasmid (7000 copies) to droplets containing a single DNA-NP and found that the latter gave about 2.5times higher eGFP expression (Figure 4c). Traces of free DNA molecules that co-purified with the DNA-NPs showed negligible levels of eGFP expression (background droplets in the right panel of Figure 4b). Importantly, although the protein levels produced using a single DNA nanoparticle as a template were broadly distributed (coefficient of variation, $\mathrm{CV}=0.33$ ), the overall yield of in vitro expressed protein was much higher than could be obtained from a single DNA plasmid (Figure 4c). These results indicate that a DNA nanoparticle produced from a single-copy template contains a sufficiently large number of functional gene copies to afford high yields of protein.

Condensed DNA structures, in the form of hydrogels, have similarly been shown to increase RNA and protein yields in vitro. ${ }^{[15]}$ Taking advantage of the densely packed DNA structure, conventional DNA purification techniques can be used to separate DNA-NPs from the original reaction components (salts, enzymes). Such an option will be important for performing sequential multi-step reactions ${ }^{[16]}$ that are inhibited or incompatible with standard biochemical conditions. As exemplified previous work, ${ }^{[10]}$ the DNA amplification mix may inhibit the subsequent protein synthesis step because of differences in salt concentration, $\mathrm{pH}$ values, and other components. Nonetheless, purified DNA-NPs not only retain their compact structure but also, by virtue of the large number of clonal gene copies, significantly increase the yield of protein produced in vitro.

The importance of in vitro protein synthesis is easy to appreciate in the context of directed evolution, proteomics, synthetic biology, or various types of screening assays that rely on cell-free systems. In addition, DNA nanoparticles can be combined with hydrophobic materials to exploit numerous drug-delivery applications. ${ }^{[17]}$ Consequently, this type of biomaterial may offer attractive possibilities for a range of biochemical and biomedical applications.

\section{Acknowledgements}

The authors are grateful to Eita Sasaki for support with TEM imaging, Algirdas Selskis for assistance with SEM, and Lina Mikoliunaite for help with AFM imaging. R.G. holds a SciexNMS fellowship. This work was supported by a LithuanianSwiss Research and Development cooperation program (grant no. CH-3-SMM-01/03).
Keywords: DNA - microfluidics - nanoparticles . protein expression $\cdot$ pyrophosphate

How to cite: Angew. Chem. Int. Ed. 2016, 55, 3120-3123 Angew. Chem. 2016, 128, 3172-3175

[1] E. A. Ottesen, J. W. Hong, S. R. Quake, J. R. Leadbetter, Science 2006, 314, $1464-1467$.

[2] N. R. Beer, B. J. Hindson, E. K. Wheeler, S. B. Hall, K. A. Rose, I. M. Kennedy, B. W. Colston, Anal. Chem. 2007, 79, 8471-8475.

[3] B. Vogelstein, K. W. Kinzler, Proc. Natl. Acad. Sci. USA 1999, 96, 9236-9241.

[4] K. A. Heyries, C. Tropini, M. VanInsberghe, C. Doolin, O. I. Petriv, A. Singhal, K. Leung, C. B. Hughesman, C. L. Hansen, Nat. Methods 2011, 8, 649-U664.

[5] A. S. Devonshire, I. Honeyborne, A. Gutteridge, A. S. Whale, G. Nixon, P. Wilson, G. Jones, T. D. McHugh, C. A. Foy, J. F. Huggett, Anal. Chem. 2015, 87, 3706-3713.

[6] D. Pekin, Y. Skhiri, J. C. Baret, D. Le Corre, L. Mazutis, C. Ben Salem, F. Millot, A. El Harrak, J. B. Hutchison, J. W. Larson, D. R. Link, P. Laurent-Puig, A. D. Griffiths, V. Taly, Lab Chip 2011, 11, 2156-2166.

[7] F. Bizouarn, Methods Mol. Biol. 2014, 1160, 27 - 41.

[8] F. B. Dean, J. R. Nelson, T. L. Giesler, R. S. Lasken, Genome Res. 2001, 11, $1095-1099$.

[9] a) Y. Shimizu, A. Inoue, Y. Tomari, T. Suzuki, T. Yokogawa, K. Nishikawa, T. Ueda, Nat. Biotechnol. 2001, 19, 751-755; b) H. Asahara, S. Chong, Nucleic Acids Res. 2010, 38, e141; c) S. A. Lesley, M. A. Brow, R. R. Burgess, J. Biol. Chem. 1991, 266, 2632-2638.

[10] L. Mazutis, A. F. Araghi, O. J. Miller, J. C. Baret, L. Frenz, A. Janoshazi, V. Taly, B. J. Miller, J. B. Hutchison, D. Link, A. D. Griffiths, M. Ryckelynck, Anal. Chem. 2009, 81, 4813-4821.

[11] J. W. Sperow, O. A. Moe, J. W. Ridlington, L. G. Butler, J. Biol. Chem. 1973, 248, 2062-2065.

[12] a) V. N. Danilevich, V. V. Artemov, S. S. Smith, R. V. Gainutdinov, A. L. Mulyukin, J. Biomol. Struct. Dyn. 2014, 32, $1979-$ 1992; b) V. N. Danilevich, A. V. Machulin, A. V. Lipkin, T. V. Kulakovskaya, S. S. Smith, A. L. Mulyukin, J. Biomol. Struct. Dyn. 2015, 33,1-15; c) K. E. Shopsowitz, Y. H. Roh, Z. J. Deng, S. W. Morton, P. T. Hammond, Small 2014, 10, 1623-1633.

[13] a) G. Z. Zhu, R. Hu, Z. L. Zhao, Z. Chen, X. B. Zhang, W. H. Tan, J. Am. Chem. Soc. 2013, 135, 16438-16445; b) R. Hu, X. B. Zhang, Z. L. Zhao, G. Z. Zhu, T. Chen, T. Fu, W. H. Tan, Angew. Chem. Int. Ed. 2014, 53, 5821-5826; Angew. Chem. 2014, 126, $5931-5936$.

[14] J. B. Lee, J. Hong, D. K. Bonner, Z. Poon, P. T. Hammond, Nat. Mater. 2012, 11, 316-322.

[15] N. Park, S. H. Um, H. Funabashi, J. Xu, D. Luo, Nat. Mater. 2009, $8,432-437$.

[16] a) L. Mazutis, J. C. Baret, P. Treacy, Y. Skhiri, A. F. Araghi, M. Ryckelynck, V. Taly, A. D. Griffiths, Lab Chip 2009, 9, $2902-$ 2908; b) M. Ryckelynck, S. Baudrey, C. Rick, A. Marin, F. Coldren, E. Westhof, A. D. Griffiths, $R N A$ 2015, 21, 458-469.

[17] a) K. Ding, F. E. Alemdaroglu, M. Borsch, R. Berger, A. Herrmann, Angew. Chem. Int. Ed. 2007, 46, 1172-1175; Angew. Chem. 2007, 119, 1191-1194; b) F. E. Alemdaroglu, J. Wang, M. Borsch, R. Berger, A. Herrmann, Angew. Chem. Int. Ed. 2008, 47, 974-976; Angew. Chem. 2008, 120, 988-991.

Received: December 21, 2015

Published online: January 28, 2016 